\title{
Prophetic medicine is the cheapest, safest and the best remedy in the prevention and treatment of hypertension (high blood pressure) - a mini review
}

\begin{abstract}
Prophetic medicine or Medicine of the Prophet (peace be upon him) comprises the divinely inspired words of therapy of Prophet Muhammad (peace is upon him). The Prophet (pbuh) did not speak a single lie in his lifetime. He made specific statements on 37 ailments and 61 medicinal plants, herbs and shrubs while making prescriptions for the sick people, out of which Nigella sativa is the most important for healing. Therefore, although the Prophet's arrival was not as a physician or pharmacist he was inspired by Allah (God) to make nearly 1000 statements on healing for the benefits of humankind, because, man needs to remain well, free from sickness to fulfill his brief mission on earth. However, it is amazing that not a single statement of the Prophet (pbuh) is found to be contradictory to the basic principles of modern medical science. The Qur'an says, "He does not speak anything of his own desire. It is only a Revelation revealed". So, traditions of the Prophet (pbuh) on healing are also true, and modern science has proved it through research after 14 centuries. About Nigella sativa (black seed) Abu Hurayrah (ra) narrates that the Prophet (pbuh) said: "Hold on (use this seed regularly)! Because it is a remedy (cure) for every disease except death."

This amazing statement generated tremendous interest among the world's scientific community. Their question was, how an unlettered man of the desert without having any pen and paper, could make such a wonderful statement on medical science? The Prophet (pbuh) did not have to carry out any laboratory research to make this statement. Moreover, the Prophet (pbuh) made the statement at a time when there was no chemistry, no science, and no pharmacy. The statement finally led the global scientific community to carry out extensive phytochemical and biological investigations on Nigella sativa seed and its oil. However, the researchers after having carried out hundreds of scientific researches around the globe finally came to the conclusion that this tiny plant seed can effectively cure 129 different types of ailments including 17 types of cancers, diabetes, AIDS and hypertension. This large number of diseases curable by Nigella sativa demonstrates the authenticity of the Prophet's statement.
\end{abstract}

Abu Hurayrah (ra) narrates another hadith which the Prophet (pbuh) said, "Allah (God) did not send down a disease without having sent down its cure."

This Prophetic statement indicates that Allah (God) has already created remedies for every disease. He created the remedies first, then the disease. But all remedies are yet to be discovered by scientists. The Prophetic tradition further indicates that since high blood pressure and hypertension are the two diseases, they are not incurable. Recent scientific research shows that Nigella sativa can effectively cure hypertension and blood pressure within eight weeks without causing any harmful side effects. Therefore, in this paper the learned readers will be enlightened with findings of modern scientific researches about how black seed can effectively cure hypertension/high blood pressure.

Keywords: Nigella sativa extracts and oil, black seed, black cumin, hypertension, high blood pressure, antihypertensive agent, hypotensive action, thymoquinone, awareness, blood pressure control
Volume 3 Issue 6 - 2018

\author{
Hussain M Musharraf, M Saiful Islam Arman \\ Department of Pharmacy, Manarat International University, \\ Bangladesh
}

Correspondence: Hussain M Musharraf, Department of Pharmacy, Manarat International University, Dhaka, Bangladesh, Email dmmhqiebd@gmail.com

Received: August 03, 2018| Published: November 05, 2018

\section{Introduction}

\section{What is hypertension?}

Hypertension or high blood pressure is a serious medical condition in which the force of the blood pumping through the arteries is too high. It is a state of great psychological stress. National Institute of Health defines hypertension as a condition present when blood flows through the blood vessels with a force greater than normal. Hypertension is also defined as a persistent elevation of systolic blood pressure of $140 \mathrm{~mm}$
$\mathrm{Hg}$ or greater and/or diastolic blood pressure of $90 \mathrm{~mm} \mathrm{Hg}$ or greater. Hypertension is a major risk factor for cardiovascular, cerebrovascular and renal diseases. It can strain the heart, damage blood vessels, and increase the risk of heart attack, stroke, kidney problems, and death.

Centers for Diseases Control and Prevention reveals that in the United States, about 77.9 million (1 out of every 3 ) adults have high blood pressure. Among adults age 20 and older in the United States, for non-Hispanic whites, 33.4percent of men and 30.7percent of women have high blood pressure. ${ }^{1}$ 
American Heart Association published a news on January 31, 2018 that more than 100million Americans have high blood pressure report that only about half (54\%) of these people have their high blood pressure under control. ${ }^{2}$ High blood pressure is also called the "silent killer" and many people do not know they have it. That's why it is important to check your blood pressure regularly. ${ }^{2}$

Arun Chockalingam published an article on worldwide epidemic of hypertension in the Canadian Journal of Cardiology in 2006. Researchers report that hypertension is one of the primary risk factors for heart disease and stroke, the leading causes of death worldwide. Recent analyses have shown that as of the year 2000, there were 972 million people living with hypertension worldwide, and it is estimated that this number will escalate to more than 1.56 billion by the year 2025. According to the researchers, awareness, prevention, treatment and control of hypertension is a significant public health measure. ${ }^{3}$

A global brief on hypertension: The Global brief on hypertension, published on the occasion of World Health Day 2013, describes why, in the early $21^{\text {st }}$ century, hypertension is a global public health issue. It describes how hypertension contributes to the burden of heart disease, stroke and kidney failure and premature death and disability. ${ }^{4}$

PubMed reveals that when one's heart beats, it pushes blood through the arteries to the rest of the body. When the blood pushes harder against the walls of the arteries, the blood pressure goes up. The blood pressure may be different at different times of the day. It is usually higher when one first wakes up, after exercise, or when one is under stress. Having higher blood pressure for short amounts of time is normal. However, when the blood pressure stays high for most of the time, it can cause serious health problems. ${ }^{5}$

High blood pressure treatment and prevention: High blood pressure or hypertension treatment and prevention typically involve a combination of medication and lifestyle changes. The purpose of the treatment is to keep the blood pressure below the high range. There are some people who say that lifestyle changes alone are enough to control their high blood pressure. But many prefer to take medication to reduce their high blood pressure. There are many different types of blood pressure medications with different modes of action. If one drug doesn't lower one's blood pressure enough, another might work for him. For some people, a combination of two or more drugs may be beneficial to keep their blood pressure under control. Medications for treating hypertension can be divided into several categories based on how they work.

According to a website article written and posted by Health line editorial team and medically reviewed by Judith Marcin, MD on January 30, 2018, a healthy lifestyle is the first line of defense against high blood pressure. Habits that help control blood pressure include eating a healthy diet, staying physically active through regular exercise, maintaining a healthy weight, avoiding alcohol consumption, quitting smoking, managing stress, eating less salt, quitting coffee, monitoring blood pressure at home and getting support from family and friends.

Common antihypertensive drugs: There have been a wide variety of drugs used to treat high blood pressure. The various categories of drugs that are used include diuretics, beta-blockers, angiotensin converting enzyme (ACE) inhibitors, angiotensin II receptor blockers (ARBs), calcium channel blockers, and alpha blockers etc. ${ }^{6}$

Some of the common drugs (generic names) used to treat or reduce high blood pressure areamlodipine besylate, diltiazem, lisinopril, losartan, olmesartan, valsartan, enalapril, atenolol, propranolol, metoprolol tartrate, metoprolol succinate etc. Upon administration of antihypertensive drugs blood vessels enlarge (dilate), and blood pressure is reduced. ${ }^{6}$ Reduced blood pressure makes it easier for the heart to pump blood and can improve heart failure. In addition, the progression of kidney disease due to high blood pressure or diabetes is slowed. Most of the antihypertensive drugs have strong side effects. In the $1950 \mathrm{~s}$, reserpine was one of the few products on the market to treat hypertension. It is rarely used now due to its numerous side effects and drug interactions. If one has high blood pressure, doctor may prescribe treatment options including lifestyle changes, medications and supplements. ${ }^{6}$

\section{Aim of present review study \\ Effects of commonly used anti-hypertensive drugs}

Currently it is observed that the therapeutic agents used to treat hypertension or high blood pressure is either synthetic or formulated dosage forms. The beneficial effects of modern antihypertensive drugs are well documented, but the preventive effect of most of the allopathic drugs against the complications of HTN or high BP is not always positive. Oral drugs which are commonly used for the treatment and prevention of hypertension have numerous side effects. Common side effects of beta blockers are fatigue, dizziness, and shortness of breath, impotence and low blood pressure. Side effects of other common drugs are cough, diarrhea or constipation, lightheadedness, penile erection problems, feeling nervous and tired, weak, drowsy, or a lack of energy, headache, nausea or vomiting. Over time high BP may damage the heart, blood vessels, kidneys or other organs. However, once it is detected, high blood pressure can be controlled and treatment may prevent health problems. ${ }^{7}$

Apart from these, majority of the patients with hypertension do not achieve the target control with the above therapies. Hence, they resort to alternative therapy. Furthermore, in the event of excess dosage it causes hypotensive effects. On the other hand, research shows that Prophetic medicine does not cause any harmful side effect. It is absolutely safe and natural. According to an article published in 2011 in the "American Journal of Chinese Medicine," multiple studies have confirmed there are no long-term side effects of taking black seed oil or thymoquinone orally on a regular basis. ${ }^{8}$

Therefore, the aim of this mini review study is to reveal pertinent published information about the beneficial effects of Nigella sativa, a promising medicinal plant with many therapeutic properties. Various studies have documented the protective effects of Nigella sativa on the cardiovascular system against the damaging effects of various reactive oxygen species (ROS), protecting the heart from cardiotoxicity as well as reducing adverse effects in hypertension. Therefore, this Prophetic remedy can be considered a safe and effective alternative to modern medicine for the prevention and treatment of HTN. It is imperative that the alternative cure should be effective, free from side effects, easily usable and affordable (inexpensive).

In view of the global scenario in this paper, we shall make a humble comparison between these two types of therapies from scientific points of view and highlight the benefits and advantages of Prophetic medicine over modern medicine in treating hypertension. We then come out with an opinion as to why Prophetic medicine is the safest, cheapest and the best remedy in the management of hypertension or high BP. Management includes both prevention and treatment. In the next few pages we shall discuss about the background of healing with the Medicine of the Prophet (pbuh), benefits and complications of 
using modern antihypertensive drugs, high cost and life-long duration of conventional treatment and treatment using Prophetic medicine. We shall also make necessary citations to modern literatures as well as divine literatures on the usage and beneficial effects of Nigella sativa in treating HTN. We hope the international scientific community will welcome the publication as a treasure of knowledge, because the topic is the first of its kind. We are confident that the information provided in this paper will be a major break-through in future HTN research.

\section{The Qur'anic concept of healing}

The Qur'anic concept of healing is that Allah is the Healer, and the doctors and the medicines are the means of healing. This concept of healing signifies that a physician diagnoses an ailment and prescribes medicine(s); a pharmacist prepares the medicines and dispenses them to the patient. Ultimately, it is Allah (God), who heals the ailment through the medicine. Thus, pharmacy and medicine, disease and treatment, and patient and physician are all interrelated in the process of healing, which is done by Allah in whom full trust should be placed. In support of this in the tongue of Prophet Ibrahim (AS) the Qur'an says: "And when I am ill, it is He who heals (cures) me".

\section{High cost of modern HTN treatment}

Apart from the common side effects of modern antihypertensive drugs usually experienced by patients during treatment, post therapy complications are also much. The conventional HTN treatment is very expensive. For patients not covered by health insurance, hypertension treatment typically costs between $\$ 740$ and $\$ 1,200$ or more per year, with an annual average cost of $\$ 454$ for doctor's visits, and $\$ 407$ for prescription medication, according to a report by the Agency for Healthcare Research and Quality. ${ }^{10}$

A doctor may also recommend additional tests such as blood tests $(\$ 10-\$ 150)$ or an electrocardiogram $(\$ 500-\$ 3000)$, also known as an EKG or ECG. Additional costs may include visit to a nutritionist to improve diet as lifestyle measures to help control high blood pressure.
The treatment may also continue over a long period of time. That is why more and more people are now looking for alternative high BP cures. Most patients with HTN are not aware of the availability of any effective alternative medicines, which are also inexpensive and safe. Prophetic herbal medicine is one of such alternative HTN cures.

From the above we understand that cost of modern drugs for HTN for a period of one year varies from $\$ 950-3,500$ or even more, which most HTN patients cannot afford, whereas less than $\$ 10.00$ will be adequate for the HTN therapy using Nigella sativa. This remedy is widely perceived as natural and safe. It is a divine gift of Allah to mankind. It is more affordable and easily obtainable. Black seed is available in every country with little efforts. The great advantage of this medicine is that hypertensive patients do not need to remain admitted in hospitals. The treatment can be done at home at almost zero cost.

\section{Duration of modern HTN treatment}

So far there is no standard treatment to achieve required correction of high blood pressure in many patients. Hypertensive patients who use modern drugs on regular basis are aware of the fact that they have to continue taking the medications as long as they are alive. In other words, using modern medicine HTN or high BP is not curable, but controllable. Nigella sativa on the other hand was proven to cure high BP in about six months' time without causing any harmful side effects. ${ }^{11}$

\section{Greatest statement of the Prophet (pbuh) on healing}

The Prophet (pbuh) made specific statements on 65 medicinal plants, herbs and shrubs, out of which statement on Nigella sativa (black cumin, black seed) is the most important. About black seed Abu Hurayrah (ra) narrates that the Prophet (pbuh) said:"Hold on (use this seed regularly)! Because it is a remedy (cure) for every disease except death". ${ }^{11}$

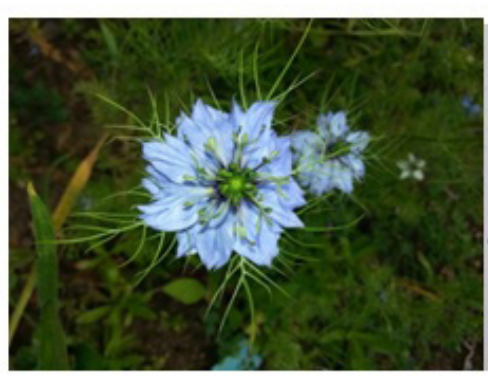

Black seed flower

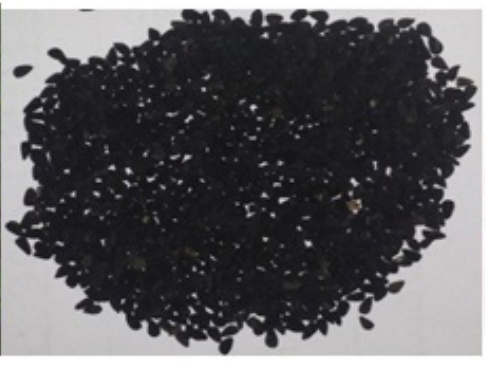

Black seed
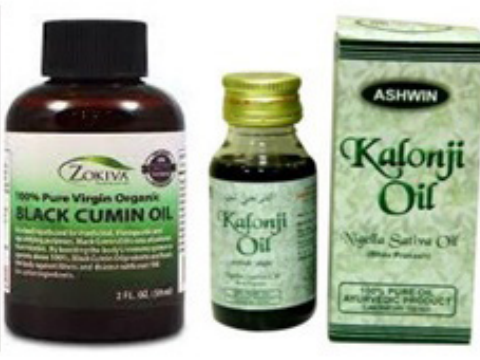

Black seed oil
The above statement indicates that God (Allah) has already created remedies for every disease except death. No scientist, doctor or physician has created any disease or ailment. Physicians can only examine a patient on the basis of symptoms and manifestations of diseases and prescribe commonly available medicines. In another Prophetic tradition narrated by Zaid ibn Aslam (ra), the Prophet (pbuh) said, "..............He Who has created disease has also created its remedy." $"$

\section{Modern views about the plant Nigella sativa linn}

The Arabic name of Nigella sativa Linn. Is HabbatusSawda or 'Habbat al Baraka'. The name Nigella sativa comes from the Latin word, nigellus, meaning black. It is translated as 'Seeds of Blessing'. The seed is called black cumin or black seed in English, while in old Latin it was called 'Panacea' meaning 'cure all'. It is known as
'Kalijeera' (Bangladesh), 'Kalonji' (in India) and 'Hak Jung Chou' (China). The Common English name for Nigella sativa is Love in a Mist. Nigella sativa is a member of the Ranunculacae family.

\section{Modern scientific researches on Nigella sativa}

Black seed is one of the earliest cultivated plants in human history, which means it was one of the early providers of life. Black seed has been used for more than 2000 years for a wide array of diseases including diabetes, Alzheimer's disease etc. Originally it was used for allergies, asthma and migraines, but as the world began to discover its many wonderful qualities, studies and research projects spread. "Calling black cumin a magical cure would certainly be an exaggeration, but it is almost impossible not to exaggerate its effectiveness." $" 13$ 


\section{Tremendous interest generated among the international scientists}

The Prophet's statement that 'black seed is cure for every disease except death', generated tremendous interest among the world scientific community. The scientists' concern was how an unlettered man of the desert of Saudi Arabia without any pen and paper could make such a wonderful statement on medical science? The Prophet (pbuh) did not have to carry out any laboratory research to make this very statement on medical science. The statement finally led the global scientists and researchers to carry out extensive phytochemical, pharmacological, microbiological and toxicological studies on black seed and its oil.

\section{Black seed can cure I 29 different kinds of diseases}

However, it was amazing that the researchers after conducting hundreds of researches around the globe finally came to the conclusion that not a single statement of the Prophet (pbuh) is found to be contradictory to the basic principles of medical science. In other words, the Prophet's statement was found to be one hundred per cent true. Today we know through scientific researches that black seed can cure 129 different kinds of diseases including diabetes, hypertension, AIDS and cancer. ${ }^{14}$ This large number of diseases curable by black seeds demonstrates the authenticity of the Prophet's statement.

\section{Popularity of Nigella sativa over time}

Although there were more than 400 herbs in use before Prophet Muhammad (pbuh), and recorded in the herbals of Galen and Hippocrates, black seed was not one of the most popular remedies of that time. Since black seed is now considered "a remedy of the Prophet (pbuh), its usage and popularity have increased significantly. Currently modern scientists have begun to acknowledge that black cumin (Nigella sativa Linn) is one of the most potent natural medicines known to science. It is the only plant seed on which highest number of scientific researches has been carried out around the world. Recently 'Australian New Crops Info 2016', listed interesting plants of the World and reported the popularity of Nigella sativa over time. Two histograms were drawn, which show the trend (five databases) 1901 2013. During the last 113 years from 1901 to 2013, there have been 1489 scientific papers published. ${ }^{15}$ From 2013 to 2018 the researches conducted on Nigella sativa is huge, thus pointing to the figure to rise above 10,000 .

Due to the great importance attached to the Prophet's statement, more than 200 universities have conducted scientific research projects on black seeds since 1959 for the award of degrees to students. In fact, researchers have acknowledged that there is no plant extract that is known to have such a wide range of healing capabilities as black cumin. Today due to findings of modern research, many modern scientists classify it as: all-in-one therapy, cure-all herb, a universal remedy and a magical herb. US researchers have also confirmed the benefits of black seeds, and they have written the first report on the anti-tumor effects of black seeds. The title of the report is 'Study of the Effects of Nigella (Black Seeds) on Humans. ${ }^{16}$ Many books have been written on black seed. ${ }^{17}$

\section{Review of scientific rearches done on hypertension using Nigella sativa}

Indonesian Researchers conduct clinical trials using Nigella sativa on the blood pressure of elderly patients This clinical trial study conducted in Geriatric Outpatient Clinic of CiptoMangunkusumo
National Hospital, Jakarta, Indonesia, was sponsored by Indonesia University. Eligibility criteria are men and women over 60 years old and available to participate in the study for 4 weeks with blood pressure higher than 140/90. Researchers conducted a randomized, double blind, placebo-controlled trial to prove the effect of Nigella sativa seed extract in elderly patients with hypertension. It was found that a dose of $300 \mathrm{mg}$ Nigella sativa seed extract twice daily had antihypertensive effect in the blood pressure of elderly patients suffering from hypertension. ${ }^{18}$

\section{Blood pressure lowering effects of black seed oil in healthy volunteers}

This study was conducted by ${ }^{19}$ to explore the effects of Nigella sativa oil on blood pressure (BP) in healthy volunteers. In a doubleblind, randomized study, 70 healthy volunteers aged 34 to 63 years with systolic BP from 110 to $140 \mathrm{~mm} \mathrm{Hg}$ and diastolic BP from 60 to $90 \mathrm{~mm} \mathrm{Hg}$ were randomly allocated to receive $2.5 \mathrm{~mL}$ Nigella sativa oil or placebo two times a day for 8 weeks. The systolic and diastolic BPs, body mass index and blood levels of aspartate transaminase, alanine transaminase, alkaline phosphatase, and creatinine and blood urea nitrogen were determined at baseline and endpoint. Results showed that in Nigella sativa oil treated group the systolic and diastolic BPs decreased significantly compared with baseline and placebo group at the endpoint. No adverse effects were reported. In conclusion, the authors revealed said that oral daily administration of $5 \mathrm{ml}$ black seed oil to healthy volunteers for 8 weeks lowers systolic and diastolic BPs without any adverse effects. ${ }^{19}$

\section{Clinical trials using Nigella sativa}

Research published in the Journal of Hypertension assessed the effectiveness of black seed in lowering blood pressure by combining the results from 11 clinical trials involving 860 people. Some of these studies used black seed powder while some used black seed oil, and compared their effectiveness in lowering blood pressure against an inactive placebo. The trials lasted from 4 to 12 weeks. On average, those taking any black seed supplements saw their blood pressure fall by $3.26 / 2.80 \mathrm{mmHg}$ compared with placebo. The study reports that those using black seed powder appeared to have a slightly greater reduction than that taking black cumin seed oil. ${ }^{20}$

\section{Mechanism of action of Nigella sativa in reducing high blood pressure ${ }^{21}$}

Reveal that the exact mechanism on how Nigella sativa reduces BP is not exactly known. The antihypertensive effects of Nigella sativa may be due to the many active compounds, each with distinct mechanisms of actions. There are several possible mechanisms involved in BP reduction, which include cardiac depressant effect, calcium channels blocking property, and diuretic effect. In the paper researchers have summarized the effects of Nigella sativa and its active compounds on BP. The researcher's further report that increases in oxidative stress has been associated with the pathogenesis of hypertension. Increase of blood pressure is due to an imbalance between antioxidants defense mechanisms and free radical productions. $^{21}$

Dr Sarah Brewer reveals that the way in which black cumin seed lowers a high blood pressure is not fully understood. Black cumin seed is believed to have a relaxant effect on smooth muscles and may act like a calcium channel blocker to dilate blood vessels. Other researchers suggest black seed extracts may help the heart pump more efficiently, or that black seed has a diuretic action. ${ }^{22}$ 
Researchers reported that the cardiovascular protective effects of Nigella sativa in hypertension are possibly contributed by its multitude actions including cardiac depressant, diuretic, calcium channel blockade, and antioxidant properties. They concluded that Nigella sativa and its active constituents have been documented to exhibit antioxidant, hypotensive, calcium channel blockade and diuretic properties, which may contribute to reduce blood pressure. This suggests a potential role of Nigella sativa in the management of hypertension, and thus we hereby recommend that more clinical studies should be conducted in a systematic manner on a large scale to evaluate its efficacy and effectiveness. ${ }^{21}$

\section{Dosage of black seed for high BP used in clinical trials}

It has been reported ${ }^{23}$ that in clinical trials using black seed powder, the doses used varied between $500 \mathrm{mg}, 1 \mathrm{~g}, 1.5 \mathrm{~g}$ and $2 \mathrm{~g}$ per day. In studies using black seed oil, doses varied between $5 \mathrm{ml}, 200 \mathrm{mg}$ and $3 \mathrm{~g}$ oil per day. In general, the higher the doses, the greater the effect. As a pharmacist, I suggest starting with a lower dose and then slowly increasing the dose. Some products are more concentrated than others. Black seed oil is 2.5 times stronger than the seed. So, one should not exceed the stated doses. None of the clinical studies have reported serious side effects. A few people have experienced mild nausea with black seed oil which resolves on lowering the dose. ${ }^{23}$

\section{Nigella sativa seeds are the most inexpensive and effective remedy for reducing hypertension}

A professional study reports that black seeds can lead a person with hypertension to perfect blood pressure in just a few weeks. Two different test groups established that $100-200 \mathrm{mg}$ of Nigella sativa extracts twice a day reduce hypertensions symptoms notably. Nigella sativa is typically touted as a natural remedy for several health problems. These include asthma, bronchitis, high blood pressure, inflammation, migraine, rheumatoid arthritis, pancreaticcanceretc. ${ }^{24}$

Conducted a randomized, ${ }^{23}$ double-blind, placebo-controlled trial to evaluate the efficacy of treatment with an oral Nigella sativa seed extract supplement in patients with mild HTN. Subjects were randomized into three groups: a placebo and two test groups that received 100 and $200 \mathrm{mg}$ of Nigella sativa extract twice a day. After 8 weeks, systolic blood pressure (SBP) values in both case groups were found to be significantly reduced when compared with the baseline values for each group. In addition, extract administration reduced both SBP and DBP in a dose-dependent manner. No complications caused by Nigella sativa were observed. The results suggest that the daily use of black seed extract for 2 months may have a blood pressurelowering effect in patients with mild HTN. ${ }^{23}$

\section{Treatment of high blood pressure using black seeds}

In a small study published in 2008, researchers found that Nigella sativa may help keep blood pressure in check. After eight weeks of twice-daily treatment with Nigella sativa extract, patients with mild hypertension had a greater reduction in blood pressure (compared to those assigned to a placebo supplement). The daily use of 100 and $200 \mathrm{mg}$ of black seed extract, twice daily, for 2 months, was found to have a blood pressure-lowering effect in patients with mild hypertension. $^{24}$

\section{Oral Nigella sativa seed extract supplement in patients with mild HTN}

Dehkordi FR, Kamkhah AF conducted a randomized, double-blind, placebo-controlled trial to evaluate the efficacy of treatment with an oral Nigella sativa seed extract supplement in patients with mild HTN. Subjects were randomized into three groups: a placebo and two test groups that received 100 and $200 \mathrm{mg}$ of Nigella sativa extract twice a day. After 8 weeks, systolic blood pressure (SBP) values in both case groups were found to be significantly reduced when compared with the baseline values for each group. In addition, the decrease in SBP in the two case groups was statistically significant relative to the placebo group. In addition, administration of the seed extract reduced both SBP and DBP in a dose-dependent manner. No complications caused by Nigella sativa were observed. The researchers concluded that hypertension (HTN) is a lifestyle-related disease and dietary modifications are effective for its management and prevention. ${ }^{25}$

Alireza Mohtashami and Mohammad Hasan Entezari in a review study evaluated the effects of Nigella sativa supplementation on lipid profiles, glycemic control, blood pressure (BP), and some anthropometric indices in humans. A search on published studies was done by using databases including PubMed, Google Scholar, Thomas Reuters Web of Science and Cochrane. After analyzing several articles, it was found that in 4 trials Nigella sativa reduced BP. Fasting blood sugar (FBS) was reduced significantly in 13 studies. ${ }^{26}$

It was also shown that Nigella sativa contains several chemicals (such as thymoquinone) that provide antioxidant activity and diuretic effect, which may play roles in reducing hypertension. ${ }^{27}$

\section{Antihypertensive effects of Nigella sativa oil in L-NAME-induced hypertensive rats}

Kamsiah Jaarin conducted a study to determine whether the blood pressure-lowering effect of Nigella sativa might be mediated by its effects on nitric oxide, angiotensin-converting enzyme, heme oxygenase and oxidative stress markers. Twenty-four adult male Sprague-Dawley rats were divided equally into 4 groups. One group served as the control (group 1), whereas the other three groups (groups 2-4) were administered L-NAME $(25 \mathrm{mg} / \mathrm{kg}$, intraperitoneally). Groups 3 and 4 were given oral nicardipine daily at a dose of $3 \mathrm{mg} / \mathrm{kg}$ and Nigella sativa oil at a dose of $2.5 \mathrm{mg} / \mathrm{kg}$ for 8 weeks, respectively, concomitantly with L-NAME administration. ${ }^{28}$

\section{Discussion of the published results on hypertension}

Hypertension can cause few symptoms until it reaches the advanced stage and poses serious health problems with lifelong consequences. Hypertensive patients are required to take drugs for life to control the hypertension and prevent complications. Some of these drugs are expensive and may have adverse reactions. Hence, it is the right time to examine scientifically, alternative therapies that are more effective and with minimal undesirable effects. Nigella sativa has been used as a traditional medicine for the treatment of hypertension for many years with no report of adverse effects. Therefore, we opine that further studies should be carried out on humans to confirm its efficacy. It is an important area for further research and development to determine the efficacy of Nigella sativa alone in the treatment and prevention of HTN. At the same time studies should also be conducted combining Nigella sativa with other antihypertensive drugs to investigate their possible synergistic effects and preferable pharmacological properties. We further recommend that since the remedy has been reported to cure all ailments except death, then why shouldn't we accept it with reason and introduce it in the public health sector as the best medicine for the treatment of HTN. 


\section{A Note to the medical scientists}

It is important to mention it here that using Prophetic medicine does not need any prescription from a physician or approval from FDA or WHO. This Prophetic remedy is obtained from an herb which has been proved to be very safe throughout centuries. It is available in almost every kitchen. It is a pity that despite having thousands of scientific researches carried out on the efficacy and beneficial effects of Nigella sativa in humans, no university or government research organization has undertaken any systematic large scale clinical trial program using human volunteers. ${ }^{29-32}$

\section{Conclusion}

In view of the global scenario of hypertension, we urge the medical scientists of the developed countries to consider Nigella sativa for conducting systematic and organized clinical trial for the use of black seed in high blood pressure, cancer, diabetes, AIDS and other human ailments without wasting any time, and WHO and FDA should approve it as commercial drug without any patent right for the interest of health of the humankind. From the above research findings on the effects of black seed on hypertensive patients we strongly believe that in order to bring complete cure to millions of hypertensive people around the world we need to look for safe and effective alternative cure for hypertension. Black seed therapy is one of such alternative effective cures for hypertension. We hope using this divine remedy the large number of HTN patients in various countries of the world will get rid of this disastrous disease at no cost, and live happily and peacefully for the rest of their life.

\section{Acknowledgements}

None.

\section{Conflict of interest}

The author declares there is no conflict of interest.

\section{References}

1 Chockalingam A, Campbell NR, Fodor JG. Worldwide epidemic of hypertension. Can J Cardiol. 2006;22(7):553-555.

2 Merai R, Siegel C, Rakotz M, et al. CDC Grand Rounds: A Public Health Approach to Detect and Control Hypertension. MMWR Morb Mortal Wkly Rep. 2016;65(45):1261-1264.

3 Chockalingam A, Campbell NR, Fodor JG. Worldwide epidemic of hypertension. Can J Cardiol. 2006;22(7):553-555.

4 A global brief on hypertension. 2013.

5 Heekin RD, Shorter D, Kosten TR. Current status and future prospects for the development of substance abuse vaccines. Expert Rev Vaccines. 2017;16(11):1067-1077.

6 Omudhome Ogbru, Jay W Marks. High Blood Presssure Drugs: Side Effects, Types, Uses and Names. 2017.

7 Mayo clic staff. High blood pressure dangers: Hypertension's effects on your body. 2016.

8 Dana severso. Side Effects of Black Seed. 2017.

9 The Holy Qur'an, Chapter Ash-Shu'ara 26:80

10 High Blood Pressure Treatment Cost.

11 Sahih Al Bukhari, Chapter Disease, Patient and Treatment Hadith No. 71: 591,592, 5277; Muslim, Chapter Salam Hadith No. 5579; Ahmad, Musnade Abu Hurayrah (ra), Hadith Nos. 7557, 9467, 10048; Ibn Majah, Chapter Treatment Hadith No. 3447.
12 Za'adulMa'ad. A Guide to Substance Abuse Services for Primary Care Clinicians. 1997

13 Peter Schleicher, Mohamed Saleh. Black Cumin: The Magical Egyptian Herb for Allergies, Asthma, and Immune Disorders. 2000.

14 Deena AS Hussain, M Musharraf Hussain. Nigella sativa (black seed). Net Journals. 2016.

15 Hussain AS Deena, Muhammad Musharraf Hussain. Prophetic Chemo Is the Safest, Cheapest and Most Effective Alternative to Modern Chemotherapy for the Cure of all Forms of Cancers - A Review. $J$ Cancer Sci Ther. 2018;10(5).

16 Hussain MM Ali, M Umar. The Pharmaceutical and Chemical Journal. 2018.

17 Hussain MM. Prophetic medicine is the safest, cheapest and most effective alternative to highly active antiretroviral therapy for the prevention and treatment of aids-a review. EJPMR. 2018;5(9):56-75.

18 Listing of Interesting Plants of the World: Nigella sativa. 2014.

19 Hassan AS, Ahmed JH, Al Haroon SS. A study of the effect of Nigella sativa (Black seeds) in isoniazid (INH)-induced hepatotoxicity in rabbits. Indian J Pharmacol. 2012;44(6):678-682.

20 Sylvia Luetjohann. The Healing Power of Black Cumin.1998.

21 Effect of Nigella Sativa Seed extract on the blood pressure of elderly with hypertension. 2011.

22 Fallah Huseini H, Amini M, Mohtashami R, et al. Blood pressure lowering effect of Nigella sativa L. seed oil in healthy volunteers. Phytother Res. 2013;27(12):1849-1853.

23 Cikman O, Ozkan A, Aras AB, et al. Radioprotective effects of Nigella sativa oil against oxidative stress in liver tissue of rats exposed to total head irradiation. J Invest Surg. 2014;27(5):262-266.

24 Sahebkar A, Soranna D, Liu X, et al. A systematic review and metaanalysis of randomized controlled trials investigating the effects of supplementation with Nigella sativa (black seed) on blood pressure. $J$ Hypertens. 2016;34(11):2127-2135.

25 Leong XF, Rais Mustafa M, Jaarin K. Nigella sativa and Its Protective Role in Oxidative Stress and Hypertension. Evid Based Complement Alternat Med. 2013;2013:120732.

26 Sarah Brewer. Black cumin seed for high blood pressure. 2018.

27 Farshad RD, Amir FK. Antihypertensive effect of Nigella sativa seed extract in patients with mild hypertension. Braz J Med Biol Res. 2006;39(4):421-429.

28 Wong Cathy ND. Nigella Sativa, Health Benefits, Uses, Side Effects \& More. 2018.

29 Dehkordi FR, Kamkhah AF. Antihypertensive effect of Nigella sativa seed extract in patients with mild hypertension. FundamClinPharmacol. 2008;22(4):447-452.

30 Mohtashami A, Entezari MH. Effects of Nigella sativa supplementation on blood parameters and anthropometric indices in adults: A systematic review on clinical trials. J Res Med Sci. 2016;21(3).

31 Khattab MM, Nagi MN. Thymoquinone supplementation attenuates hypertension and renal damage in nitric oxide deficient hypertensive rats. Phytother Res. 2007;21(5):410-414.

32 Jaarin K, Foong WD, Yeoh MH, et al. Mechanisms of the antihypertensive effects of Nigella sativa oil in L-NAME-induced hypertensive rats. Clinics (Sao Paulo). 2015;70(11):751-757. 